Session 1653

\title{
A Course on Freshman Survival Skills
}

\author{
Dr. Paul Blowers \\ Department of Chemical and Environmental Engineering \\ The University of Arizona
}

\begin{abstract}
The University of Arizona has created a year-long, one credit seminar course for freshmen and transfer honors students who are beginning their educational careers in engineering. This course is designed to make students aware of the opportunities that lie ahead of them and to give them some skills to help them deal with adversity. The topics covered in this course, along with some representative assignments will be discussed.
\end{abstract}

Because our University's job fair comes early in fall semester, our first few lectures are centered on resume development. The next round of topics covers learning styles and teaching styles to help students find methodologies that may help them learn material more effectively. Following sessions highlight student leadership opportunities, how to take college exams, how to work in teams, time management skills, dealing with personal conflicts, and resources on campus for finding information. The second semester covers topics that include algorithms and their use in engineering education, consensus building, presentation skills, interviewing tips, graduate school and how to prepare for admission, research positions on campus, mentoring and being mentored, and lifelong learning.

Course topics were selected with an eye towards when students would make the best use of the materials. Also, short assignments were selected to encourage the students to reflect upon our discussions and take positive actions in their daily activities. Students are encouraged to contribute to all discussions and to provide input on other topics they would like to see in the course.

Approximately 90 students begin the first semester course, with most continuing on through the second semester. Students have consistently selected this course as the most useful course from their first year and strongly urge other students to participate in future offerings.

\section{Introduction}

Over time, the characteristics that can be used to describe freshmen entering engineering programs has shifted with many schools seeing a demographic shift in engineering student populations over the last few decades. Instead of classrooms being almost exclusively filled with male students, women now make up significant percentages of our engineering courses ${ }^{1-3}$. We also now have many more minorities in our engineering courses. Besides being more diverse in gender and race, students also appear to have higher entrance exam scores than several years

Proceedings of the 2002 American Society for Engineering Education Annual Conference \& Exposition Copyright O2002, American Society for Engineering Education 
ago $^{4-5}$ However, there are some things about our entering students that have not changed over time, mainly having to do with their preparation for college.

Even though we have seen an upward trend in student SAT scores ${ }^{4}$, many of our entering students are still not able to do simple algebra. Despite having taken advanced high school mathematics, students just are not able to do math once they reach college, which has been a long standing problem ${ }^{6}$. Other students may not be able to write a complete sentence or have an appropriate science background to begin engineering ${ }^{7}$. Other students may be unable to cope with daily stresses ${ }^{8}$ or to plan for their future.

Amazingly, many students assume that their high school degree has given them every tool they need in order to succeed in college. Very few students have a clear idea of what college will be like once they get there because they have done almost nothing else to prepare for their first college courses beside complete high school. Many of the students will also be unprepared for independent living and having to manage their own development. They believe that college is an extension of high school where the teacher will make you study in order to pass the class.

There is a whole set of learning skills that students have to quickly assimilate in order to do well in their first few semesters at college?. These learning skills include the ability to solve problems and not to rely on the "plug and chug" methods that may have served them well in high school. They also need to learn how to communicate effectively and how to prioritize their tasks using effective time management. They must become proficient at interacting with new people and with team members because much of their learning will involve collaborative learning projects. Many students may not have been challenged with their high school experiences and will not even know how to study.

In addition to all these learning skills, students often are lacking life skills that help them survive in college. These life skills include being able to manage their finances so their bills get paid on time and they don't incur large levels of credit card debt ${ }^{10-14}$. Other skills may sound trivial but their absence will certainly contribute to student stress and time management problems. These skills include how to do laundry, how to cook, how to use computers effectively, and how to go about choosing a major.

\section{A Course to Help Students to Adjust to College}

The University of Arizona offers a one credit colloquial seminar course to freshmen and transfer students who are in the honors program and have declared engineering as their college. The class meets for one hour every week and has approximately 90 students enrolled each semester. An older version of the course involved student tours to different labs within the college, but did not appear to be useful for the students. The new version of the course is discussion oriented and covers issues to help students make the transition to college. The discussions are led by the professor, but are mainly driven by student participation.

Figure 1 shows a complete list of the topics that are covered in the first semester of the colloquial seminar series. This is also the order in which the topics are covered. You can see 
that the topics range over a wide variety of issues that could be of interest to beginning college students. The topics also offer a balance between life skills, like time management and creating a resume, to learning skills like how to take exams and studying strategies.

Selling Yourself on Paper: How to Create a Resume.

What is your Learning Style?

Resumes Revisited.

Using your Learning Style to your Best Advantage.

Student Leaders Panel Discussion.

Maximizing Success: How to Take Engineering Exams to Maximize Your Grade.

What Good is an Internship Anyway?

Teamwork Projects: Group Leader or Group Packmule.

Teamwork Project: How to Work as a Group to Delegate Tasks.

Time Management Skills.

Roommate Conflicts (and Conflicts with Others).

Study Strategies to Try when Nothing Seems to be Working.

Resources on Campus You Don't Know How to Use (but will make it easier for you to succeed).

Last Class - Course evaluations and goodbye for now.

Figure 1 - Topics covered in ENGR 196a, Fall Semester, 2001. An Honors

Course called Survival Skills for Freshmen Engineers

III. How the Course is Structured

Careful thought was put into how and when the topics would be covered throughout the semester. Resume activities are covered first because the university-wide career fair comes extremely early in the semester and students should have a resume ready before then. We also cover learning styles early in the semester in order to help themselves figure out why some courses or professors may seem harder than others and what they can do to help them succeed in the course ${ }^{15-16}$. When the students are approximately one-third of the way through the semester we discuss how to take engineering or college exams. This scheduling ensures that students have already taken and received results on their first round of exams.

Most of the students are in our freshmen introductory engineering course simultaneously with the course described in this paper. This other three credit course is designed to introduce students to design and teamwork issues. Because the students must complete three team projects during the semester, we spend two days talking about how students can become leaders on their projects and how to achieve results. Time management skills are also covered at this point. Students will have settled into routines with their time so it is useful to have them keep track of where their time goes for a week. We then discuss roommate conflicts, how to study when nothing seems to be working, and how to use resources on campus to help them succeed.

Again, the course is heavily discussion oriented. All opinions are valued and students are often able to give advice to each other to help them get past the problems they have encountered. Students are routinely encouraged to offer up their experiences to the others. A consistent theme though all of the assignments and discussion is self-assessment and creating a feedback loop to 
effect lasting improvements. The failure of "magic" or "quick fixes" to actually cause longlasting change is also brought up as an issue.

Although this class is only a one credit course that meets once a week, homework is still required for more than half of the meetings. All of the homework is designed to cause selfevaluation and to encourage positive changes that will lead to becoming more successful students. This is done so that we can emphasize life-long learning as a tool that can be applied without needing external input from others.

\section{Some Sample Topics and Their Homework}

The first topic that we cover in the freshmen seminar is how to construct a resume. This is done early in the semester because the campus-wide career fair occurs within the first month of classes. Most of the students will have done a resume at some point, but will not have done one that is necessarily suitable to give to a large corporation. The discussion begins by asking the students to form small groups and then list all of the sections or pieces of information they would choose to include on their resume. We then list all of the students' ideas on the board.

Now that students have critically thought about what must be included on their resumes, we go through a short discussion on details about some of those sections. The details include how to list a GPA, how to write an objective, and how to describe activities that may not necessarily describe the jobs they have held. Full details are available at: http://www.che.arizona.edu/Directory/Faculty/Blowers/ENGR196b/Resume/resume.htm This website also shows a sample freshman resume and this same student's resume after another year. This student is allowing the class to view an anonymous version of his/her resume so they can see how a resume evolves over time and how some categories change. Students have commented that this is a very useful motivator that encourages them to get out and look for career related experience.

The student assignment after our discussion is shown in Figure 2. Here, the students have to develop a resume and then submit it in the correct format online in addition to bringing a copy to class the following week.

\section{Resume Development Homework}

Based on the discussion today, develop a resume that will most effectively sell yourself to a company. Submit a paper copy in class and email a copy in Word or pdf format to blowers@engr.arizona.edu.

Stress skills that you have learned on the job or in volunteer positions that will be transferable to your new job. Format the resume to be pleasing to the eye and easy to follow.

We will critique the resumes in a follow-up session.

Figure 2 - An example of a homework problem to have students develop a resume, learn how to attach a file to email, and begin the course.

The web-based version is requested for two reasons. First, students need to become proficient at all uses of computers and this assignment may be the first time that they have electronically mailed an attachment. Second, many of the online submissions will be used in a follow-up meeting to show pros and cons of different formats that students have chosen to use. In the past two years, extremely long or short resumes have been selected, along with those that violate

Proceedings of the 2002 American Society for Engineering Education Annual Conference \& Exposition Copyright O2002, American Society for Engineering Education 
some of the general rules of thumb of creating a resume. Students are asked to evaluate these resumes that have been made anonymous so that their peers can use that information to improve their resumes. The written version is returned to the students with specific suggestions for improvements.

On this year's course evaluations, students suggested making this resume comparison even more interactive. Students suggested that we break the class up into teams of four human resources personnel and have each team evaluate the same resumes and rank them from "most likely to interview" to "never interview". Then the groups will offer up their results and share their reasoning with the other groups. The people who offered up this idea thought that our large class discussions may intimidate some students and prevent them from contributing their ideas to the class. The small group format would encourage shy students to participate before an extrovert from the group would present the results. This suggestion will be included in the class next year.

Another one of the early topics we discuss in our class is how learning styles can prevent or improve student learning when various teaching styles are used. Students are assigned to take Felder's online learning style test ${ }^{17}$ and to bring their results into class on the day when we are going to discuss learning styles, as shown in Figure 3. To receive credit, they must turn in a hard copy of their results.

Discussion begins by having all of the different engineering majors find each other and form a group. This activity not only gets the students into groups, but encourages them to begin working with the classmates they will have once they reach the next round of classes that are discipline specific. The groups are asked to do an analysis of their results to see if they all have similar or disimilar learning styles as a group. Then we compile all of the group results on the board and find the statistical distribution of each of the major four categories.

Most students did not take the time to read the background information on learning styles so we do a discussion of each category and how it may affect their learning in each course. Most people from a general population are global learners while most engineering graduates are sequential learners ${ }^{18}$. We discuss whether or not engineers change over time to become more successful in the courses which are predominantly taught in a sequential teaching style, or whether the global students are self-selecting themselves out of engineering. We also discuss the fact that almost ninety percent of the students in the class are visual learners, but almost none of 
our courses are taught utilizing strong visual tools. We mention that it is possible that engineering students are learning style chameleons that "converge" to the learning style best suited for their situation and these students are retained in engineering.

This entire discussion is done to introduce students to the idea of what learning styles are and how they can overcome some of their learning challenges. Approximately 25 to 30 percent of the students in the course have encountered these ideas at some point in the past, but the majority of the students have not. We discuss how students can use different textbooks that may fit their learning style as a supplement to a text that does not fit their style. We also talk about using study groups with others from different learning styles that can help translate the materials into their learning styles. Finally, external resources like using a teaching assistant or tutor that can explain things in a way different from the lecture or book can help.

The last activity we will discuss in this paper involves taking exams in college, specifically engineering exams. Many of the students in the freshman honors course will not have been challenged in their high school courses. College may be the first time that they have to study and it may also be the first time they find themselves doing far below the class average on exams. We spend one period discussing how students can do well on exams in college. In particular, we cover time management during the exam, how to earn partial credit, and how to

\section{Taking Exams}

We've talked about some strategies to help you succeed on your exams today. Look back over your recent exams and analyze your performance based on how you might have done with these strategies in mind. What could you have done differently to earn more points?

Why did you perform as you did on your worst test so far? What are your biggest barriers to success and how might you address them?

Again, think critically about how you learn, how you are being tested, how you study, and your time commitments. Brainstorm areas where you can improve and list one concrete strategy you will try for your next exams.

Figure 4 - A homework for reflection on the results of past exams and concrete strategies to improve. maximize your score when you are unable to complete an early part of a multi-part question.

The homework assignment for this week is shown in Figure 4. Students are asked to review the exams that they have had returned by their professors and evaluate their performance on the exams. Students are asked to explain why they performed poorly on their worst exam so far and to identify the barriers that stood in the way of their success with that material. Then students are asked to list different strategies they could use on the next exam in that class. Students submit their written comments and receive additional feedback about other strategies they can try.

Several students commented this year that this particular lecture was the

most useful for them while other students thought they already knew how to succeed on exams. Again, the wide distribution of student abilities led to some very prepared students who have come from strong technical high schools, while others are barely prepared to begin trigonometry or english at the college level. At least seven students said that the focused discussion on how to 
take exams enabled them to raise their grade by 30 percent or more on the follow up exam in their most difficult course.

\section{Student Comments about the Topics Covered}

Students were asked to evaluate the course in a final assignment at the end of the semester. The questions asked of the students are shown in Figure 5. Students were first asked to rank the topics we had covered from most useful to least useful and give each topic a numerical ranking. The student rankings of the topics were compiled and an average rank for each topic was found for the entire class. The results from this analysis are shown in Figure 6.

1) Rank the topics that we covered this semester from most useful to least useful? Give a brief description of why you ranked the topics this way.

2) What aspects of the course were most beneficial for you this semester?

3) What topics would you choose to include in this class?

4) Describe one activity that we could do in class that would make one of the topics more informative/more exciting than it was this semester.

5) What common theme(s) did you notice throughout the semester that tied the topics together?

Figure 5 - A final open-ended course evaluation by the students.

In Figure 6, a lower score means that students ranked it near number one as the most useful topic, while a higher number means that the topic was ranked as less useful. Most students ranked creating a resume as the most useful activity or topic that we covered during the semester. While some students felt they had already developed a viable resume, many students clearly did not.

It was suprising to see how the next six topics fell so close to each other in ranking. Learning styles was slightly more useful to some students while our discussion about internships, time management, exam strategies, teamwork, and how to study were all very close in ranking to each other. A closer look at the rankings showed that students were split among their past experiences within these topics. This led to a fairly even distribution of rankings and overall averages that were very similar.

Two topics in particular stood Topic Average Rank by Class:

\begin{tabular}{ll}
\hline Resumes & 2.3 \\
Learning Styles & 4.5 \\
Internships & 4.6 \\
Time Management & 5.2 \\
Exam Strategies & 5.5 \\
Teamwork & 5.6 \\
Studying & 5.6 \\
Resources in the Library & 6.7 \\
Student Leader Panel & 8.4
\end{tabular}

Figure 6 - A student ranking of the usefulness of topics. A rating of one would mean all students in the course thought that topic was most useful. A higher number indicates that students thought the topic was less useful.

out as distinctly less useful for the students. We had one topic on how to use resources in the library and on campus to find highly specific information. The low student ranking on the discussion and the follow up homework are justified by some of the internal problems with the construction of the topic. An informational specialist from the library came into our class and

Proceedings of the 2002 American Society for Engineering Education Annual Conference \& Exposition Copyright O2002, American Society for Engineering Education 
discussed how to look for information on the library's website and online search tools, demonstating on a large projector how to do so. She also covered how to be more efficient at these searches. Because students were not able to manipulate the website themselves at this time, much of the effectiveness of the lecture was lost. Students were then asked to form into groups of four within their individual disciplines so that they could do the homework.

The homework assignment is a series of 40 highly specific questions about a wide range of scientific and non-scientific topics. Students are asked to find information like street directions between two locations or a specific address for a company. Questions like these are relatively easy to search for online, while many of the other questions are not. For instance, students are asked to find at least five current journals received by the library that have at least one article about bridges. Students rarely think to go to the library and physically browse through the journals and instead rely almost solely on the online resources where a search like this becomes tedious. Other information they were asked to find is incorrect on the web which allows us to discuss the fact that even a "reliable" and "honest" source of information online may just have incorrect information.

The major problems involving this topic were timing issues and the classroom discussion. Students commented that the discussion would have been much more useful if they were given the list of questions a week earlier and asked to come up with a list of their own questions for the librarian. They also would have liked to meet in a multi-media room where they could follow along and explore the library website with the librarian as she explained how to find information. Then the students would be given a week to complete the assignment. This suggestion is a very good one and we are seeking a suitable multi-media room for ninety students where they can access the web simultaneously. The completion of our new Integrated Learning Center for Freshmen may allow us to inplement the students' suggestions.

The primary problem with this topic, though, was that it was discussed immediately prior to Thanksgiving and the group assignment continued through the Thanksgiving break. Students said they were not able to work with their groups because they were out of town. Another complaint was that since the university was closed over break they could not access the physical library resources. Next year, this topic will be assigned so that it does not overlap Thanksgiving Break to alleviate these concerns.

\section{Student Comments About Other Topics of Interest}

Students were asked to suggest topics they wish we had covered during the semester to help them succeed. The student comments were aggregated and Figure 7 shows the results. We see that a large percentage of the students wanted help on choosing a major. They felt their experiences in another freshmen engineering course were not enough to aid them in making sure they had selected the right major. Another large percentage of students said they wanted help on more communication skills. Specifically, the students said they would like some way to get interviewing experience or help with their technical writing skills.

Professional development topics also were very common among the students. Students asked if we could have human resources specialists from companies come in and give their input 
on what skills are needed in the workplace. They also wanted a panel of engineers to come in to assess their resumes or talk about what they did on the job. Students also wanted advice on how to look for a research position on campus or how to get involved with various professional societies on campus.

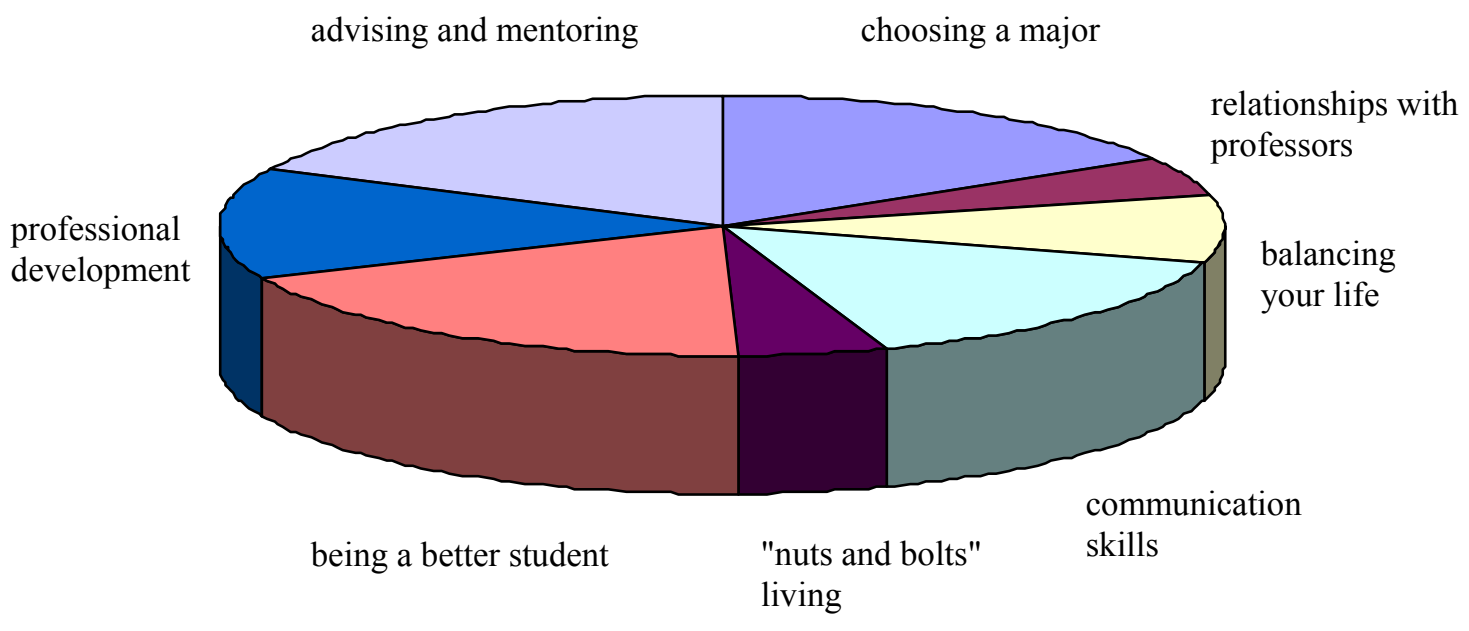

Figure 7 - A categorical grouping of additional topics that students wished had been in the first semester course upon it's completion.

Another large section of the class made recommendations to discuss how to become better students. They had many specific topics that would be possible to include like a discussion of the resources that are available within the College of Engineering to help them succeed. They also wanted to know about organizations and locations where they could receive tutoring. Other topics would be very difficult to discuss, like how to navigate the bureaucracy of the university or how to be organized or persistent.

Advising and mentoring were mentioned as several topics to include. Students suggested long term planning of their education and finding scholarships as primary topics while finding a mentor and using your advisor effectively were also mentioned. Some students also wanted just general information about what a BA degree is versus a BS degree. Again, we are seeing the wide diversity of preparation that students have coming into the university.

Three categories received fewer nominations but still occured four times or more. Several students wanted advice on "Nuts and Bolts" living. This includes topics from budgeting money to eliminating procrastination to methods of boosting confidence. In another category, some students wanted help with balancing their lives so they could do well in school, still have fun, work, and manage relationships. Finally, relating to professors was mentioned as a topic to include. Here, students wanted to know how you approach a professor to initiate a dialogue while others wanted to know how to deal with problem professors or how to use office hours effectively.

Proceedings of the 2002 American Society for Engineering Education Annual Conference \& Exposition Copyright O2002, American Society for Engineering Education 
One can see that there was a wide range of topics the students were interested in. However, all of these topics could be collapsed down into several major categories that represent the areas where students are having difficulties or have questions that were unanswered during the first semester of the course. Students clearly are not comfortable with how to interact with professors and wanted to know how to get advising help or how to communicate with us effectively. Students are also seeking validity on their major choice and would like more resources to settle their minds. Students realized from the resume exercise that they must develop activities that will reflect a well-rounded and competent engineer so they were interested in professional development topics and in how to maintain a healthy life-balance for success.

All of the student
comments were used to
generate a list of topics that
will be taught in the second
semester of the course. These
topics are shown in Figure 8 .
The highlighted topics deal
specifically with student
comments while the normal
text topics obliquely deal with
some of them. Again, we only
meet once a week for fifteen
weeks so not every topic could
be included. The most
commonly cited suggestions
for topics were chosen while
topics where the author has
little expertise were not.

The Rubik's Cube and Algorithms in Engineering Education Algorithms and How to Develop Them Consensus Building and Teamwork

Presentation Skills: Tell Them ${ }^{3}$ Interviewing Well: How to Get Hired Interviewing Skills II: Practice with the Tough Questions Grad School and How to Get In Presentation Skills: Good and Bad and In Between Leadership Opportunities and Ways to Build your Resume Search and Research: How Can you Get Involved? Mentoring: Being Mentored Mentoring: Being the Mentor Lifelong Learning Last Class - Course evaluations and goodbye

Figure 8 - A list of topics to be covered in the second semester of the course. Highlighted topics are ones strongly recommended by students in the first semester.

VII. More Suggestions from the Students on How to Improve the Class

Again, Figure 5 showed the evaluative questions the students were asked to complete at the end of the course. Students were asked to describe an activity that we could do in class that would be more effective at covering any of the topics. Students generated a diverse and rich compilation of activities that could be used for different topics and we will only highlight a few of them here.

We already mentioned that students suggested that they meet in small teams to evaluate resumes. The benefits of this activity versus the large-scale discussion we did this semester is that shy students will interact with others. There were several variations on this theme with some students wanting to compete against the other groups to come up with a ranking the entire group agreed on that could be supported by comments. Others wanted a mock job fair where some students were human resources specialists while the other students were job seekers. The HR workers would evaluate and rank resumes. Another suggestion was to require the students to go to the job fair to submite their resumes to companies. This activity would be very difficult to 
grade because there would be no way of ensuring the students had indeed given out their resumes to companies. Also, it would be a bad idea to send ninety freshmen to a career fair and overwhelm the recruiters.

For the internship discussion, students wanted to go to the career fair as a class, but this again has the above mentioned problem. Other students wanted human resources specialists to come into our class to discuss how they view resumes and what is important. Others wanted to have some small group time with the students who came into our class to talk about their past internship experiences. Finally, another group of students wanted to have companies come in to talk about what they get out of their internship programs. Many students just do not see why a company would hire a student who does not have a degree yet.

Learning styles generated many suggestions from the students. Their activities ranged from having the students evaluate their professors' teaching styles and discuss that in small groups to having students with different learning styles explain a difficult concept to each other and then discuss why it was easy or hard to understand. Other students wanted a quiz that emphasized different learning styles on different problems and then see if their scores from the questions matched well with their survey-based results.

Students also wanted a quiz in class before we discuss exam taking strategies. They suggested several scenarios that they have apparently encountered during their first semseter of college. Several students wanted a really hard quiz with an impossible first problem that is only worth 10 points that is followed by three easy questions worth the other ninety points. Others wanted to have a multipart question where they couldn't answer the first part but were expected to use that answer on the rest of the question.

For teamwork activities, students either wanted interactive group activities or a dicussion. They suggested breaking the class into teams to complete a task. Students would then have to evaluate their progress as a team in completing the exercise. For discussion, students wanted to hear more from their peers about how to deal with difficult team members so a smaller group exercise would be more beneficial than the large-scale lecture we had done. Some other students suggested that we have some role playing exercises where students were given extreme situations to respond to or a conflict to resolve.

We already discussed the library resources assignment and how students suggested improving it. Students certainly want timely hands-on activities that will reinforce their learning, so students want us to physically go to the library or have a tour before the assignment. Based on all of the student comments, we will do a general introduction to library resources next year, followed by a shorter version of the information scavenger hunt. Then students will be able to ask questions about how to find information. Finally, the master question list will be assigned for the groups to solve over the following non-holiday week.

There were many other idas the class generated that don't really fit within any of the topics we discussed this semester. These concepts are more meta-activities that bridge more than one topic or don't really fit within the current classifications. Quite a few students wanted to meet new students so they wanted activities that would accomplish this. Others wanted to have 
upperclassmen from their majors come into the class so they could meet with them in small groups to find out how to get through the program. They were also interested in what things the upperclassmen would do differently if they could go back and do it all over again. Students also wanted to see senior design projects or to take tours of their departments. Another freeform activity they suggested was to have the class write down questions and concerns they have about college life or classes and then have the rest of the class offer advice on how to deal with their question.

As an aside at this point, we as faculty often fear the feedback that students may give to us on evaluation forms. The comments here show that students are not only willing but very capable in helping us generate better classes so that we will be more effective at what we do.

\section{Course Themes}

As a final assessment question, students were asked to list the theme(s) that tied all of the materials from the semester into a coherent whole. The only intentional theme that was built into the course was self-assessment for improvment. However, students saw many other themes as well. It was common for students to use the course title of Survival Skills for Freshmen Engineers as their theme. Other excerpts were that:

- "I've noticed that your career and success are what you make of it."

- "I have learned to maximize my college experience in order to enhance my success in an engineering career."

- "My future is in my hands, but there are people to help, skills to learn, and things to do."

- and, "Each topic developed a theme of preparation, informing us of the challenge and difficulties that stand ahead of us, allowing us to prepare for them now."

The wide range of themes the students saw in the course shows where they feel they have the most to gain. They tended to see a theme in an area where they did not feel very confident in their ability to succeed.

\section{Final Comments and Conclusions}

Students offered up additional feedback on the course on their evaluations although they were not expressly asked to do so. Their comments show that this course is a valuable addition to their learning experiences at this point in their academic careers:

- "I had more information in this 1 credit course that I normally have in a 3 credit course!"

- "I am always amazed at how far engineers plan ahead. It was nice to have a class that helped in planning for success."

- "The class was not a 'data dump' where you simply poured knowledge into our heads, but rather the topics sought to expand our understanding and allowed us to make connections between different aspects of our education."

In conclusion, different students found that different topics from throughout the semester were more useful than others. The general consensus was that learning how to develop a resume was their most useful topic. Many of the other topics ended up with an average rating near five 
because students brought different backgrounds into the course. They overwhelmingly liked that the class was discussion oriented and was not just another lecture. Students in general thought that they had learned how to learn better, which would lead to better retention of students within engineering and lead to better students overall.

The complete syllabi and homework for the two semester course is available at: http://www.che.arizona.edu/Directory/Faculty/Blowers/ENGR196b/index.htm

References:

1. Brown, N. W. and E. J. Cross, Jr., "Descriptions of Self and Engineers by Male Engineering Students", Psychol. Rep., 78, 179-186 (1996).

2. Butler, B. R., and W. K. LeBold, "Introducing Freshmen to Engineering: A Model Course", Engr. Educ., 739742, April (1979).

3. databytes, By the Numbers, ASEE Prism, 14, Sept. (2000).

4. Levinson, A., Associated Press, August 29, 2000, "Average Math SAT Score Highest Since 1969, http://edreform.com/news/000829sp.htm

5. The Condition of Education 1996, Supplemental Table 22-2. http://nces.ed.gov/pubs/ce/c9622d02.html.

6. Peressini, A. L. and R. W. Bokenkamp, "Sharpening the Math Skills of Engineering Freshmen", Engr. Educ., 745-747, April 1979.

7. Foster, R. J., "Retention Characteristics of Engineering Freshmen", Engr. Educ., 724-728, April (1976).

8. Gohn, L., J. Swartz, and S. Donnelly, "A Case Study of Second Year Student Persistence", J. Coll. Student

Retention, 2, 271-294 (2000-2001).

9. Kelley, C., Editor, Essentials of College Living: Curriculum Guide, Postsecondary Education Consortium, Knoxville, TN, (1999).

10. D'Agostino, D. M., "Consumer Finance: College Students and Credit Cards. Report to Congressional

Requesters", U.S. District of Columbia, (2001).

11. Stanford, W. E., "Dealing with Student Credit Card Debt", About Campus, 4, 12-17 (1999).

12. Stanford, W. E., "Dealing with Student Credit Card Debt", Student Aid Transcript, 10, 4-9 (1999).

13. Pinto, M. B., D. H. J. Parente, and T. S. Palmer, "College Student Performance and Credit Card Usage", J. Coll.

Stud. Devel., 42, 49-58 (2001).

14. Munro, J., and J. B. Hirt, "Credit Cards and College Students" Who Pays, Who Benefits?", J. Coll. Stud. Devel., 39, 51-57 (1998).

15. McCaulley, M. H., "Psychological Types in Engineering: Implications for Teaching", Engr. Educ., 729-736, April (1976).

16. Bron, N. W., and E. J. Cross, Jr., "A Comparison of Personality Characteristics for Engering Freshmen, Persistors and Norm Groups in Engineering", Educ. and Psychol. Meas., 52, 939-944, (1992).

17. http://www2.ncsu.edu/unity/lockers/users/f/felder/public/ILSpage.html

18. McCaulley, M., "Dveloping Critical Thinking and Problem-Solving Abilities", J. E. Stice, Edictor, New Directions for Teaching and Learning, 30, Jossey-Bass, San Francisco, 36--72 (1987).

\section{PAUL BLOWERS}

Paul Blowers is an Assistant Professor in the Department of Chemical and Environmental Engineering at the University of Arizona. He received his B.S. in Chemical Engineering from Michigan State University before attending the University of Illinois at Urbana-Champaign for his M.S. and Ph.D. in Chemical Engineering. His other research involves using quantum chemical techniques for predicting reaction rates in different environments.

Proceedings of the 2002 American Society for Engineering Education Annual Conference \& Exposition

Copyright O2002, American Society for Engineering Education 